\title{
Ciencia y economía \\ en el Nuevo Reino de Granada. Las comisiones de Sebastián José López Ruiz, 1778-1803*
}

José Antonio Amaya

Profesor Asociado de la Universidad Nacional de Colombia (Colombia). Correo electrónico: jaamaya@ unal.edu.co. El autor es Sociólogo por la Universidad Nacional de Colombia, sede Bogotá (Colombia); Magíster y Doctor en Historia por la École des Hautes Études en Sciences Sociales (Francia); candidato a Magíster en Gestión Documental y Administración de Archivos por la Universidad Internacional de Andalucía (España). Entre sus publicaciones recientes figuran: "Enrique Umaña Barragán (1771-1854): su conversión de presunto sedicioso en leal funcionario del rey (1794-1809)" en Revista Historia de la Educación Latinoamericana, Vol. 16, No. 23 ( (2014) y "Ciencia y política en la Nueva Granada" (Bogotá: Maremagnum, 2014). Entre sus temas de interés se destaca la historia de la ciencia, de las bibliotecas y de la lectura Nueva Granada segunda mitad del siglo XVIII, así como la matodología de la historia.

\section{James Vladimir Torres Moreno}

Afiliado institucionalmente a Georgetown University (Estados Unidos). Correo electrónico: jvt7@georgetown.edu. El autor es Historiador por la Universidad Nacional de Colombia, sede Bogotá (Colombia) y especialista en Economía de la Universidad de los Andes (Colombia). Entre sus publicaciones recientes figuran: "El comportamiento de los precios en una economía preindustrial: Popayán, virreinato de Nueva Granada, 1706-1819” en Cuadernos de Economía, Vol. 34, No. 66 (2015) y “Monedas de antiguo y nuevo cuño. Envilecimiento y reacuñación en el Nuevo Reino de Granada en la segunda mitad del siglo XVIII" en Memorias y sociedad Vol. 18 No. 36 (2014). Entre sus temas de interés están historia económica, historia monetaria, historia de la ciencia, historia colonial, historia del siglo XIX.

Recibido: 28 de febrero de 2016

Aprobado: 20 de marzo de 2016

Modificado: 2 de mayo de 2016

Artículo de investigación científica

DOI: http://dx.doi.org/10.15648/hc.29.2016.8

* $\quad$ Este artículo forma parte del proyecto: "Ciencia y Economía en el Nuevo Reino de Granada. La inversión en ciencia del Estado virreinal, 1775-1810”. financiado por la Convocatoria de Investigación Orlando Fals Borda, Facultad de Ciencias Humanas, Universidad Nacional de Colombia (Colombia). Agradecemos la colaboración de Monsieur Michel Lille, investigador independiente; Ramiro Sánchez Coral y Diego Ortiz Vallejo, historiadores de la Universidad Nacional de Colombia, sede Bogotá (Colombia) y de Julián Rendón Acosta, estudiante de Sociología-Historia, Universidad Nacional, sede Bogotá (Colombia).

Esta publicación está bajo una licencia Creative Commons Reconocimiento-NoComercial 4.0. 
Ciencia y economía en el Nuevo Reino de Granada. Las comisiones de Sebastián José López Ruiz, 1778-1803

\title{
Resumen
}

La investigación propone establecer, analizar y explicar el costo de las comisiones (17781803) puestas por el rey Carlos III (1716-1788) bajo la responsabilidad del médico y naturalista panameño Sebastián José López Ruiz (1741-1832). Por este camino busca contribuir al conocimiento del protagonismo de las autoridades virreinales en el desarrollo de las ciencias en el Nuevo Reino. Con este fin se aprovecha información recientemente ubicada en el Archivo General de Indias (Sevilla) y en el Archivo General de la Nación (Bogotá). El artículo contribuye a entender cómo y por qué la política del centralismo borbónico en materia científica fracasó en el virreinato de la Nueva Granada.

Palabras clave: quina, historia de la ciencia, historia económica, virreinato de la Nueva Granada, historia natural.

Science and economy in New Kingdom of Granada. The commissions of Sebastian Jose Lopez Ruiz, 1778-1803

\begin{abstract}
This research intends to establish, analyze and explain the cost of the commissions (1778-1803) imposed by the King Carlos III (1716-1788) under the responsibility of doctor and naturalist Panamanian Sebastián José López Ruiz, (1741-1832). With this purpose in mind, this article tries to contribute to the knowledge of the role of the viceroyal authorities in the science development of the New Kingdom. With this intention, it is taken advantage of the information recently located in the General File of Indian (Seville) and in the General File Nation (Bogotá). This article contributes to the understanding of how and why the Bourbon centralism in scientific policy failed in the Viceroyalty of Nueva Granada.
\end{abstract}

Key words: Peruvian bark, history of science, economic history, Viceroyalty of New Granada, natural history.

Ciência e economia no Novo Reino de Granada. As comissões de Sebastián José López Ruiz, 1778-1803

\section{Resumo}

A investigação propõe estabelecer, analisar e explicar o custo das comissões (1778-1803) 
postas pelo rei Carlos III (1716-1788) baixo a responsabilidade do médico e naturalista panamenho Sebastián José López Ruiz (1741-1832). Por este caminho procura contribuir ao conhecimento do protagonismo das autoridades virreinales no desenvolvimento das ciências no Novo Reino. Com este fim aproveita-se informação recentemente localizada no Arquivo Geral de Índias (Sevilla) e no Arquivo Geral da Nação (Bogotá). $\mathrm{O}$ artigo contribui a entender como e por que a política do centralismo borbónico em matéria científica fracassou no virreinato da Nova Granada.

Palavras-chave: quina, história da ciência, história econômica, virreinato da Nova Granada, história natural.

Science et économie dans le Nuevo Reino de Granada. Les commissions de Sebastián José López Ruiz, 1778-1803

\section{Résumé}

La recherche propose d'établir, analyser et expliquer le coût des commissions (17781803) confiées par le roi Carlos III (1716-1788) à la responsabilité du médecin naturaliste panaméen Sebastián José López Ruiz (1741-1832). Par cette voie, elle contribue à la connaissance du rôle des autorités vice-royales dans le développement des sciences en Nouvelle Grenade. À cet effet, sont mises à profit des informations récemment récupérées aux Archives Générales des Indes (AGI, Séville) et aux Archives Générales de la Nation (AGN, Bogotá). L'article aide à comprendre pourquoi et comment la politique centraliste des Bourbon en matière scientifique échoua en Nouvelle Grenade.

Mots clés: quinquina, histoire de la science, histoire économique, vice-royauté de la Nueva Granada, histoire naturelle.

\section{INTRODUCCIÓN. LA CIENCIA EN UNA MONARQUÍA ILUSTRADA}

Las prácticas científicas en el Nuevo Reino de Granada avanzaron durante la segunda mitad del siglo XVIII. Baste mencionar la introducción de Newton (1762), la reforma universitaria (1767-1778), la organización e inauguración de la Biblioteca Pública (1767-1777), la creación de la Expe- 
dición Botánica (1783) y un aumento de la circulación del libro ${ }^{1}$. Las comisiones gubernamentales del médico Sebastián José López Ruiz propiciaron conocimiento aplicado al incremento de la productividad de algunos sectores, en particular el comercio de las quinas santafereñas.

En este contexto la historia fiscal se proyecta en la historia política y social, y también en la de las ciencias, la educación y la cultura. Una parte significativa de los egresos del real erario se destinaron a financiar instituciones y personas que protagonizaron la creación y difusión de conocimiento en el Nuevo Reino. Las "prioridades de un monarca ilustrado"2 se concentraron en el incremento de los ingresos para financiar las guerras atlánticas e incluyeron recursos para sostener, en el terreno científico, un nuevo frente contra los rivales europeos.

La importancia de la historia fiscal en este asunto radica en que las entradas y salidas del fisco, tras ser sometidas a un proceso de depuración de stocks (remanentes del año anterior), arrojan un proxy del sector real de la economía. El análisis de dicho proxy para el Nuevo Reino indica que la economía creció durante la segunda mitad del siglo XVIII. Paralelamente, aumentó el tamaño del Estado virreinal en la economía. Los datos agregados señalan que la presión fiscal pasó de $4 \%$ del PIB en 1760 a $10 \%$ en 1800, y nada señala que este aumento sobre el ingreso disponible de los neogranadinos ralentizara el incremento de la economía.

Es indudable que hubo crecimiento. Lo que continúa generando controversia es la celeridad de su ritmo y desaceleración ulterior. Adolfo Meisel fija en 1780 el momento del cambio de tendencia en las cuentas fiscales y establece que la coyuntura del crecimiento del Estado en el PIB se prolongó hasta $1800^{3}$. Por primera vez el Nuevo Reino demostró ser capaz de

1 José Antonio Amaya, Mutis, apóstol de Linneo: Historia de la botánica en el Virreinato de la Nueva Granada (1760-1783), 2 tomos, trad. del francés José Antonio Amaya, con apoyo en una versión preliminar de $\mathrm{M}^{\mathrm{a}}$ Yolanda Medina (Bogotá: ICANH, 2006); Renán Silva, Los Ilustrados de Nueva Granada 1760-1808 (Medellín: Banco de la República, EAFIT, 2002).

2 Expresión recogida del inspirador artículo de Jacques A. Barbier y Herbert S. Klein, "Las prioridades de un monarca ilustrado: El gasto público bajo el reinado de Carlos III", Revista de Historia Económica 3 (1985).

3 Adolfo Meisel, Crecimiento, mestizaje y presión fiscal en el Virreinato de la Nueva Granada, 17611800 (Cartagena: Centro de Estudios Económicos Regionales, 2011), 72. 
remitir recursos a las tesorerías peninsulares. Luego de 1800 dicho crecimiento se frenó, siendo de crisis fiscal y económica la última década de la vida colonial ${ }^{4}$.

En este contexto de crecimiento y crisis, el ejercicio se plantea lo siguiente en relación con las erogaciones científicas: $1^{\circ}$ medir su magnitud y comportamiento; $2^{\circ}$ establecer la relación que las instituciones y personas beneficiadas establecieron con las autoridades virreinales. El logro de ambos objetivos permitirá fijar el peso relativo de estos gastos en el fisco, relacionándolo con el papel de la ciencia, la educación y la cultura en el auge fiscal de finales de siglo, y la estrategia de los responsables de estas instancias culturales con la crisis fiscal que se desató en 1800. El gasto de las cajas del virreinato en actividades e instituciones científicas es un proxy de la importancia que le reservaron los Borbones a la ciencia, la educación y la cultura, y debería arrojar luz sobre las opiniones cambiantes de los ilustrados y sus funcionarios.

Para establecer los recursos invertidos convienen algunas consideraciones acerca del funcionamiento de la Real Hacienda neogranadina para observar cómo fluía el dinero. La Caja Real, unidad básica del sistema fiscal, percibía los impuestos sobre diversas actividades jurisdiccionales de los rubros en arriendo o gestionados por funcionarios. Existían cajas subalternas, principales y matrices. Las subalternas remitían los excedentes (situados) a las principales tras descontar los gastos locales de administración. Las principales cumplían la misma función con la matriz, encargada de remitir los excedentes a la metrópoli, una vez suplidos los gastos del virreinato, incluyendo los militares de Cartagena. En la segunda mitad del siglo XVIII existían en el virreinato trece cajas principales, una matriz en Santafé y un número variable de subalternas.

Este movimiento de numerario quedaba registrado en diversos libros de caja en que destacan el manual y el mayor. El manual asentaba el flujo diario de dinero en la tesorería; el mayor condensaba el movimiento anual

4 James Torres, Minería y moneda en el Nuevo Reino de Granada. El desempeño económico en la segunda mitad del siglo XVIII (Bogotá: ICANH, 2013), 10-12. 
del cargo y data de los rubros que se dividían en "propios", "particulares" y "ajenos". Los propios constituían la "masa general o común de la Real Hacienda", es decir, el ingreso líquido disponible para satisfacer los gastos de funcionamiento del aparato colonial y otros gastos "fijos" o "permanentes". Los particulares eran flujos de caja que pertenecían a la Real Hacienda pero que tenían asignaciones presupuestales ya fijadas. Los ajenos eran ingresos administrados gubernamentalmente, aunque no pertenecían al cúmulo de la Real Hacienda.

Esta división de naturaleza patrimonial permite observar el lugar de los rubros destinados a la ciencia, la cultura y la educación en el entramado institucional de la Real Hacienda. Entre 1775 y 1810 los rubros que aglutinaban los gastos pertinentes eran los siguientes:

\section{Tabla 1.}

Ramos de la Caja Matriz de Santafé con información sobre ciencia, cultura y educación

\begin{tabular}{|l|l|l|}
\hline \multicolumn{1}{|c|}{ Propios } & \multicolumn{1}{c|}{ Particulares } & \multicolumn{1}{c|}{ Ajenos } \\
\hline Historia Natural (1783-1810) & Floras americanas (1793-1795) & Biblioteca Pública (1790-1810) \\
\hline Becas Reales (1775-1800) & & Seminario (1775-1810) \\
\hline Pagado por Reales Cédulas & & \\
\hline $\begin{array}{l}\text { Pagados en Beneficio de la Real } \\
\text { Hacienda }\end{array}$ & & \\
\hline Acopios de quina (1782-1798) & & \\
\hline
\end{tabular}

Fuente: Elaboración propia con base en: Sección Archivo Anexo I (SAAI), Real Hacienda, t. 8-16. Archivo General de la Nación (AGN), Bogotá; Santafé, 791-802. Archivo General de Indias (AGI), Sevilla

La masa de gastos de la Real Hacienda cubre varias cartas cuentas con cronologías distintas. Aquí interesan los rubros "pagados por reales cédulas" y lo "gastado en beneficio de la Real Hacienda". El primero agrupa gastos ordenados por la Corona que no generaron un desembolso ubicable en otras cartas cuentas, por ejemplo, las pensiones especiales a viudas, funcionarios y otros por méritos y servicios. El segundo engloba gastos puntuales para hacer crecer la masa común aunque sin generar nuevos impuestos. Esta información ha permitido construir las series de erogaciones en ciencia, educación y cultura de la Caja Matriz de Santafé (1775-1810), objetivo 
que se ha realizado ampliamente con la Expedición Botánica (1783-1816) . Queda pendiente idéntica tarea con la adecuación, mantenimiento y administración de la Biblioteca Pública; con las becas reales; con las exploraciones de Fray Diego García (1783-1790), sin olvidar los aportes privados en los casos citados. Es probable que el levantamiento de una buena cantidad de mapas y planos de aquella época haya sido sufragado con dineros destinados al Batallón Auxiliar o al Batallón Fijo de Cartagena. Como es fácil de alcanzar, una investigación de estas dimensiones exige desarrollo en varias etapas. El presente artículo se concentra en las comisiones de Sebastián José López Ruiz.

El rubro "Acopios de quina" o genéricamente "Quina” es otro elemento de análisis. Creado en 1782 (en el cargo) y en 1786 (en la data), buscaba asentar los flujos de caja correspondientes a la compra y venta de quina, primero a cargo de López, después de José Celestino Mutis (1732-1808) y otros, siendo objetivo último de tales compras la creación de un estanco articulado con la ciencia neogranadina. Antes de 1782, los dineros de la caja santafereña para dichas comisiones se consignaban en los movimientos de las cartas cuentas denominadas "Beneficio de la Real Hacienda" y "Pagado por pensiones y reales cédulas". Además, el rubro de "Quina" era tratado por los oficiales como "gasto extraordinario", particularmente mientras las comisiones estuvieron a cargo de López. La Tabla 2 resume los datos recuperados de la Caja Matriz.

La presente investigación busca fortalecer el diálogo entre la historia económica y la de las ciencias. Esta discusión debe contribuir a la explicación del desarrollo de la ciencia en el virreinato buscando crear una serie de indicadores que permitan calibrar el papel de las autoridades. Dichos indicadores resultarán de la comparación entre la inversión bruta del Estado, a través de la Caja Matriz de Santafé, sus diferentes cajas y el ingreso agregado del virreinato, global como per cápita. Además, ayudarán a precisar la relación del Estado con las distintas instituciones científicas, sin desconocer

5 Amaya y Torres, "La Expedición Botánica...". 
inversiones de particulares en minería e historia natural ${ }^{6}$. Hay que diferenciar entre gasto virreinal e imperial. El virreinal engloba la mayor parte de lo aquí pertinente; el imperial asumió la dotación en libros de López, por ejemplo. Las cajas de Santafé eran autónomas de Madrid, lo que contribuye a justificar su estudio. Tras instaurar mediante cédulas las comisiones de López, la Expedición Botánica o la Biblioteca Pública, Madrid delegaba la gestión a las cajas de Santafé y al virrey, suprema autoridad del reino y superintendente de Real Hacienda.

\section{López RuIz, COMISIONADO DEL REY}

Ya a principios del siglo XVIII, la sobreexplotación de los bosques de quina de Loja venía generando degradación en las remisiones del específico a Europa. La Casa del Rey conoció el riesgo de ver agotarse su stock de quina. El 20 de enero de 1776 la Corona solicitó a las autoridades coloniales pronunciarse sobre la conveniencia de establecer un estanco de quina en Loja $^{7}$. La orden ${ }^{8}$ fue recibida en Santafé el 21 de mayo de 1776 por Manuel Antonio Flórez (1722-1799), virrey desde el 3 de diciembre de 1775, quien encargó el asunto a la Junta General de Tribunales, que se reunió el 22 de mayo siguiente ${ }^{9}$. Compuesta por el virrey, el oidor más antiguo de la Audiencia, el fiscal y contador decano y uno de los oficiales reales ${ }^{10}$; tal

6 También se estimarán las inversiones en conocimiento adelantadas por Mutis en este campo. Se recuerda el viaje de Clemente Ruiz Pavón a Suecia (1773-1776), financiado por la Compañía Minera de Nuestra Señora del Rosario en el cerro del Sapo, de propiedad de Pedro de Ugarte (1726-1792), socio mayor, y Mutis. Idéntica estimación se hará con los viajes de López a Madrid: de 1777 a 1778, financiado gubernamentalmente, y de 1792 a 1795, por cuenta del interesado. Amaya, Mutis, apóstol de Linneo, 264-265; 292-302

$7 \quad$ Nicolás Prieto Dávila, "Testimonio en que se comprenden órdenes superiores e informes sobre el establecimiento del estanco de quina” (Santafé, 18 de septiembre de 1777). Santafé, 558, ff. 26-29; 32, Archivo General de Indias (AGI), Sevilla; "Decreto de Flórez para que López someta a la consideración de Miguel de Santiesteban una muestra de quina” (Santafé, 12 de agosto de 1776). Indiferente, 1554, ff. 1030v-1031, AGI; "Carlos III dispone preparar un informe sobre el estanco de la quina" (copia) (El Prado, 20 de enero de 1776). Santafé, 558, f. 27. AGI.

8 Miguel de San Martín a Flórez, "Se solicita al virrey concepto sobre el estanco de quina" (Santafé, 21 de mayo de 1776). Santafé, 558, f. 30. AGI.

9 “Orden del virrey" (Santafé, 21 de mayo de 1776). Santafé, 558, ff. 31, 38, 45 AGI.

19010 Los funcionarios de la Junta de Real Hacienda eran fiados por Ugarte, siendo la fianza requisito indispensable para ingresar y permanecer en la administración. Amaya y Torres, "La Expedición Botánica", 42-43; Nicolás Prieto Dávila, "Convocatoria a Junta de Tribunales" (Santafé, $1^{\circ}$ de junio de 1776). Santafé, 558, ff. 31-32; 38-39 AGI. 
junta buscaba fungir como "consultoría" integrada por funcionarios de menor rango.

Flórez obró con la celeridad que le dictaban la protección de los bosques de quina y el real abastecimiento. "A su inmediato arribo" a Santafé, había llamado al médico y naturalista Mutis para que atendiera a su primogénito José Antonio atacado de tercianas. Originario de Cádiz, Mutis vivía en Nueva Granada desde 1760. Aquí, tras desempeñarse como médico del virrey Pedro Messía de la Cerda (1700-1783), se había rehusado a regresar con este a España en 1772. Por Mutis, Flórez conoció la existencia de bosques silvestres de quina que el gaditano aseguraba haber descubierto en Tena (1772) y Honda (1773) ${ }^{11}$. La curación de su hijo y la noticia del descubrimiento debieron despertar la curiosidad del funcionario. Se sabía que en abril de 1773 Mutis le había presentado un arbolito de quina a Manuel de Guirior, durante la recepción que se le ofreció en Honda como virrey entrante (1773-1776), y que este prometió sembrar en el jardín del santafereño Palacio Virreinal, para simbolizar la riqueza del Nuevo Reino y celebrar en Mutis al descubridor de una planta de valor terapéutico y económico.

A la llegada de la orden, Mutis reiteró los compromisos ${ }^{12}$ que le impedían ocuparse de la quina. El virrey encontró sin dificultad a López, el "otro médico diplomado", que residía en Santafé, egresado de la Universidad de San Marcos de Lima y que se jactaba de haber descubierto la quina en Honda desde $1774^{13}$, en el camino que lo había conducido de su natal Panamá a Santafé. Flórez se guardó de impugnar la versión de López; el 7 de agosto siguiente dirigió una orden secreta a las "justicias de Guayabal,

11 José Celestino Mutis a Francisco Gutiérrez de Piñeres (Santafé, 24 de marzo de 1783). En Francisco de las Barras de Aragón, "Mutis en el Archivo de Indias", mss. cit. en Quinas de la Real Expedición Botánica del Nuevo Reino de Granada. Flora de la Real Expedición Botánica del Nuevo Reino de Granada, vol. 44, eds. Enrique Pérez Arbeláez y Francisco Fernández de Soto Morales (Madrid: Instituto de Cultura Hispánica, 1957), 22.

12 El $1^{\circ}$ de enero de 1777 Mutis abandonó la capital para ir a administrar la mina de $\mathrm{N}^{a} \mathrm{~S}^{\mathrm{a}}$ del Rosario en el Sapo; el proyecto maduraba desde 1772. Amaya, Mutis, apóstol de Linneo, t. 1, 289-290.

13 López aseguraba haber descubierto quina en Honda (Tolima) en junio de 1774. "Cronología del descubrimiento de la quina de Santafé" (Santafé, 20 de mayo de 1784). F. 184v. Biblioteca de Palacio, Madrid. 
Tena y la Mesa" para que prestaran a este "oficial de la Secretaría de Cámara" ${ }^{14}$ los "auxilios que necesitase para hacer cierta indagación"

La conocida remisión de dos supuestas especies de quina de "Tena"16, marcadas con las letras A y B, el 12 de agosto de 1776, no fue producto de la iniciativa de un particular "[a]nimado por su celo patriótico"17, sino el resultado de la gestión de un funcionario nombrado por Flórez ${ }^{18}$. Confirmar la existencia de quina en Santafé beneficiaba la carrera del mandatario. Al confiarle este asunto a López, escribano de la Secretaría ${ }^{19}$, Flórez hizo pública su protección y aseguró la lealtad del panameño. Los salarios percibidos por López desde su vinculación a la administración deben considerarse como inversión en ciencia, dado que la investigación sobre la quina es la única actividad conocida de su desempeño en aquel cargo.

Exámenes practicados en Nueva Granada validaron las colecciones de López. Flórez comunicó a Madrid la existencia de quina cerca de Santafé el 15 de septiembre de 1776. Presentó a López como descubridor, adjuntó un diagnóstico favorable preparado por $\mathrm{Mutis}^{20} \mathrm{y}$ citó el Informe sobre la quina de Loja preparado por Miguel de Santisteban en $1753^{21}$. El 23 de agosto de 1776 la Junta de Tribunales encargó a López el "corte y conducción" de 400 arrobas de quina y 8 tablones de madera en Tena (y

14 En las cartas cuentas de la Real Hacienda el cargo de Oficial de Secretaría del Virreinato está dividido en Oficial Primero, Segundo, Tercero, Cuarto Primero y Cuarto Segundo, con asignaciones anuales de 1.000, 700, 500, 500 y 400 pesos respectivamente. Joaquín Durán Díaz, Estado general del virreinato de Santafé de Bogotá en el año de 1794 (Bogotá: Banco de la República, 2012), 33.

15 "Orden", firmada por Francisco Iturrate, secretario de Flórez. Fondo Pineda, II, 2 (41), Biblioteca Nacional de Colombia (BNC), Bogotá.

16 Y no de Honda como lo señala habitualmente la historiografía. López a Flórez, "Informe" (Santafé, 12 de agosto de 1776). Fondo Pineda, II, 1 (15-40), BNC.

17 Juan Antonio Susto, "El médico y naturalista panameño Dr. Sebastián José López Ruiz (1741-1832)", Lotería 6.67 (1961): 56.

18 Susto, "El médico", 64.

19 El Escribano de Cámara devengaba 800 pesos anuales; el Secretario de Cámara 2.600. Durán Díaz, Estado general, 33.

20 Joaquín Fernández Pérez, Cristina Jiménez Artacho y José Fonfría Díaz, "Las quinas de Caldas", Actas VIII Congreso de la Sociedad Española de Historia de las Ciencias y de las Técnicas, 16-20 de septiembre de 2002, coords. José Javier Escribano Benito, Luis Español González y Ma. Ángeles Martínez García (Logroño: Universidad de La Rioja, 2004), 561 y nota 6.

21 Miguel de Santisteban al marqués de Villar, virrey del Nuevo Reino, "Relación informativa de la quina de Loxa” (Santafé, 4 de junio de 1753), en Pérez y Fernández, Quinas, 66. 
no en Honda), para "su experimento y examen en las boticas de Santafé y España”. Debiendo colectar muestras de las dos quinas, López recibió 401 pesos de las Cajas de Santafé22.

Las muestras salieron para Madrid el 15 de octubre siguiente. "La legitimidad y eficacia de la quina de Santafé" 23 fue certificada para la especie B, que no se logró con la A, que llegó “averiada”, según aseguraba el Ministro de Indias, José de Gálvez (1720-1787). Persuadidas de tener en cercanías de la capital quina idéntica a la de Loja, a mediados de 1777 las autoridades renovaron ante Madrid la necesidad de crear un estanco justificado en un "Memorial" preparado por López ${ }^{24}$.

Fortalecido por la conjunción de intereses alrededor de "su quina santafereña” y distinguido con la protección del virrey, López comenzó a gestionar el "premio con que la real munificencia [remunera] siempre el mérito" 25 . Recién avecindado en Santafé, este "hombre de grandes aspiraciones" se resistió a dimensionar las incomodidades que se estaba preparando para el resto de sus días con los contrapoderes locales. Desde antes de su creación, la comisión de López era vista con ojeriza. La élite santafereña tenía en Mutis al verdadero descubridor de la quina, viendo en el panameño a alguien que buscaba privilegios con mérito ajeno.

Madrid no tardó en recibir una denuncia sobre la calidad de López. La impugnación no era nueva. Poco antes de 1774 el Bachiller Santiago Maytín, había denunciado el "origen mulato" de López, para eliminarlo de las oposiciones para el cargo de protomédico de la ciudad de Panamá ${ }^{26}$. Este litigio complicó una controversia de López con el gobernador de Panamá

22 SAAI, Real Hacienda, t. 10, f. 491v. AGN.

23 Susto, "El médico", 57 y nota 10.

24 Pilar Gardeta Sabater, Sebastián José López Ruiz (1741-1832). Sus escritos médicos y el ejercicio de la medicina en el Virreinato de Nueva Granada durante la segunda mitad del siglo XVIII (Málaga: Universidad de Málaga, 1996), 29 y nota 73. Sin embargo, López reconocía no ser el autor del pensamiento de estancar la quina. López a Caballero y Góngora (15 de septiembre de 1782). Fondo Pineda, III, 6 (55-58), f. 56. BNC.

25 Susto, "El médico", 57.

26 Gutiérrez de Piñeres a Gálvez, por la vía reservada, "Informe de la calidad y aptitud de don Sebastián y don Juan Pablo López Ruiz” (Santafé, 31 de julio de 1782). AGI, Santafé, 661, ff. 5-7. 
por un problema de higiene ${ }^{27}$, y lo determinó a venir a Santafé a defender su candidatura ${ }^{28}$. El primer cargo de su carrera, teniente del Protomedicato de Cuzco, había revelado su carácter. "Su genio muy proclive a las disputas le hizo granjearse enemistades y poco apoyo del gobernador; renunció al cargo cuando tan solo llevaba desempeñándolo dos años", en $1766^{29}$. Su intransigencia y modo de servir la administración sin miramientos por la tranquilidad pública lo obligaron a "huir". Su extremismo era proporcional a la impotencia de sus protectores para atenuar el rechazo que suscitaba su persona y comportamientos. En Panamá, donde su familia y él mismo gozaban de la protección de la Iglesia ${ }^{30}$, la acusación de "mulato" arrojó a un segundo plano la falta de "cortesanía" y se convirtió en el motivo de sus sinsabores del momento. En Santafé la causa de su exclusión tuvo que trascender a las autoridades. La acusación procedente de esta ciudad alcanzó los oídos del monarca. El 5 de agosto de 1777 una orden reservada solicitaba al visitador general de Nueva Granada Juan Francisco Gutiérrez de Piñeres (1732-ca. 1790), una investigación sobre la calidad de López, que podría costarle la exclusión del real servicio ${ }^{31}$.

Este ataque contra López incluía a Flórez, aunque este permaneció intocado. Virrey recientemente posesionado, daba la impresión de querer gobernar en este asunto ignorando las realidades locales: usos y costumbres, afinidades y vínculos de interés preexistentes. Su actitud, considerada excesivamente frontal, despertó animosidades y provocó la alianza de fuerzas que se coaligaron subterráneamente. Estos contrapoderes de orden financiero, científico, administrativo e incluso político no tenían todavía un proyecto que oponer al de Flórez, aunque tampoco querían ver a un "extranjero mulato" gestionando una probable fuente de riqueza. Intrigarán hasta lograr su caída. Será necesario esperar el advenimiento de una nueva fuerza encarnada en la alianza de Antonio Caballero y Góngora (1723-

27 Gardeta, López, 24.

28 Amaya, Mutis, apóstol de Linneo, t. 1, 294-295; Gardeta, López, 23.

29 Gardeta, López, 23.

30 Gutiérez de Piñeres a Gálvez, "Informe sobre López" (Santafé, 31 de julio de 1782). Santafé, 661, ff. 5-7. AGI.

31 Gutiérez de Piñeres a Gálvez, "Informe sobre López”. (Santafé, 31 de julio de 1782). Santafé, 661, f. 6. AGI; "Oficio de Gutiérrez de Piñeres a Ramón de Carbajal" (copia), por la vía reservada (Santafé, 31 de agosto de 1782). Santafé, 661, f. 8. AGI. 
1796) con Mutis, quien a diferencia de Madrid sostenía la investigación taxonómica como requisito del desempeño del comisionado. Este juego de contrapoder(es) es esencial para comprender la comisión López ${ }^{32}$.

Al tanto de este nuevo contratiempo y decidido a defender sus intereses, López se trasladó a Madrid. Flórez le proveyó pasaporte, embarcación y auxilios para el viaje ${ }^{33}$. Sus protectores ${ }^{34}$ lograron que el 24 de noviembre de 1778 Carlos III lo nombrara "para que se emplee en el examen de este precioso ramo". El rey comprometió recursos adicionales para la explotación de las quinas santafereñas asignándole un sueldo anual de 2.000 pesos, además de "las cantidades necesarias" 35 para dicha comisión, concluida la cual se le concedería una pensión anual de 1.000 pesos $^{36}$.

La Instrucción del 26 de noviembre de 1778, firmada por Gálvez ${ }^{37}$, integró a López "a la Expedición Ruiz y Pavón” 38 -es decir a la Expedición al Perú, recién creada en 1777- y circunscribió su acción a los territorios de "los reinos de Santafé y Quito, para que investigue la quina" " Como ocurrió con las expediciones botánicas itinerantes, la comisión López fue

32 La lectura de Guy Thuillier, Pour un histoire de la bureaucratie en France (Paris: Comité pour l'histoire économique et financière de la France (CHEFF), 1999), una de cuyas secciones se ocupa de los contra-poderes, guía el presente análisis.

33 "Orden" y Decreto de Flórez (Santafé, 1776). Fondo Pineda, II, 4 (43-44) BNC. El caso López es excepcional. Realizó dos viajes a Madrid (1778 a agosto de 1779; junio de 1792 a febrero de 1795) y uno a Panamá (finales de 1789 a inicios de 1790). Los costos de este último ascendieron por lo menos a 2.000 pesos, que cubrió su hermano Santiago. Testamento de Santiago José López Ruiz, otorgado en Quito (24 de octubre de 1805). Protocolos, Notaría Tercera, Quito, Tomo 78, f. 166v. Archivo Nacional del Ecuador (ANE), Quito.

34 Gálvez, la Iglesia, Casimiro Gómez Ortega (1741-1818) y Antonio Palau y Verdera (1734-1793), estos últimos profesores del Real Jardín Botánico de Migas Calientes.

35 Santafé 793 , s. f., AGI.

36 Gutiérrez de Piñeres a Gálvez, "Informe sobre López” (Santafé, 31 de julio de 1782). Santafé, 661, ff. 6-7. AGI, donde se evoca "la suma facilidad, con q[u]e en estos Payses se prueba quanto se quiere, si no hay persona inmediatam[en]te interesada q[u]e se oponga".

37 Amaya, Mutis, apóstol de Linneo, t. 2, 550-557.

38 Hipólito Ruiz López (1754-1816) y José Antonio Pavón Jiménez (1754-1840).

39 Tradicionalmente se ha dicho "comisionado para el acopio de la quina"; este error procede de la lectura sin verificación de una declaración del 14 de septiembre de 1784 donde Francisco Bianchi, apoderado de López Ruiz, se refiere al "comisionado por Su Magestad para varios asuntos de su real servicio en este Nuevo Reino de Granada, especialmente para los acopios de quina por cuenta de la Real Hacienda". Notaría Segunda (Santafé), tomo 166, ff. 264-264v, AGN. Quito no era un reino, sino una audiencia dependiente de la administración civil del Nuevo Reino de Granada desde 1739. 
temporal. Su fecha inferior se definió desde el arribo de López a Cartagena de Indias (después del 28 de marzo de 1779, día en que zarpó de Cádiz ${ }^{40}$ ), y la superior en el retorno a España de los expedicionarios al Perú, previsto en Cartagena para 1781. Queriendo aumentar las colecciones del Real Jardín, y a pesar de que, como se sabe, López negaba ser naturalista, Gómez Ortega, director científico de la Expedición al Perú, lo hizo condecorar Botánico del Rey ${ }^{41}$, le encargó la Flora de Santafé, subsidiaria de la del Perú y Chile y lo dotó con una biblioteca de 74 títulos ${ }^{42}$. La Academia de Medicina de Madrid y la Sociedad Médica de París lo asociaron, el 19 de noviembre de 1778 y el 19 de julio de 1779 respectivamente ${ }^{43}$.

El 18 de enero de 1779 la Corona le ordenó a Flórez que desde su arribo a Santafé López debía iniciar el "acopio de Quinas, en la estación más oportuna y que se distribuía por cuenta de la Real Hacienda en esa capital y en las demás Provincias del Reyno, por donde no transita la de Quito y Cuenca" "44. Si alguna vez se le asoció a este asunto un aspecto terapéutico fue para consolidar la validez de la quina santafereña, creando simultáneamente un mercado no competitivo para la de Loja, y encargándole al virrey la coordinación, en asocio con "los Governadores, y Jueces Reales" locales, encargados de calcular las necesidades de la nueva demanda.

López regresó a Santafé poco antes del 6 de agosto de $1779^{45}$, sin haber logrado acallar las habladurías sobre su origen. Fundado o no, este estigma

40 Susto, "El médico", 57.

41 Informe de Mutis a Gutiérrez de Piñeres (borrador) (Santafé, 24 de marzo de 1783), en Guillermo Hernández de Alba, Archivo epistolar del sabio naturalista don José Celestino Mutis, 4 t. (Bogotá: Kelly, 1968), t. 2, 262.

42 J. A. Amaya estableció que esta biblioteca contaba títulos de botánica (27), zoología (1), mineralogía (1), historia natural (4), viajes (15), medicina (3), materia médica (4), farmacología (2), física y astronomía (1), teología (5), literatura (1), diccionarios enciclopédicos (2), diccionarios de lenguas antiguas y modernas (4) y diccionarios de historia natural, medicina y comercio (4). Amaya, Mutis, apóstol de Linneo, t. 1, 292 y t. 2, Apéndice III, documentos 4.3 y 4.4, 558-564. Sin embargo, en Susto, "El médico", 58, aparece que "salió de Cádiz el Doctor López trayendo una librería particular comprada personalmente por él en Madrid y en París y una biblioteca científica enviada por el Rey Carlos III a las autoridades coloniales".

43 Gardeta, López, 30.

44 Real Orden (copia) que Gálvez comunica a Flórez, (El Pardo, 18 enero de 1779). Fondo Pineda, XV, 3,1 (886-963), BNC.

45 En José Antonio Escallón a Mutis (Santafé, 6 de agosto de 1779) se describen parcialmente las obras de botánica traídas de Europa por López, en Hernández de Alba, Archivo epistolar de Mutis, t. 3, 247. 
aparecerá una y otra vez en su camino. Para la élite criolla y española como para altos funcionarios del virreinato, el atributo "mulato" significaba que López no era de los suyos, que carecía de la educación esperable en un patricio y que no les inspiraba confianza; en pocas palabras, que no podía integrar su red de alianzas y secretos.

\section{El DESEMPEÑo DEL COMISIONADO}

Examinar el desempeño de López requiere conocer los objetivos que se le fijaron a sus comisiones. Enseguida hay que establecer los resultados alcanzados. Lo esencial figura en la Instrucción del 26 de noviembre de 1778 y en la Orden del 18 de enero de 1779. En síntesis, López debía:

1. Formarse en botánica.

2. Corresponder con los expedicionarios al Perú.

3. Procurarse muestras de quina de Loja.

4. Identificar esta calidad en Santafé.

5. Organizar allí la recolección de quina.

6. Aprovechar sus excursiones para montar dos herbarios idénticos de plantas nuevas y útiles, y formar una Flora de Santafé.

7. Enviar a España semestralmente una de las copias del herbario acompañada de descripciones.

8. Enviar para su aclimatación toda planta útil al Real Jardín.

9. Reunirse en Quito con los expedicionarios al Perú y perfeccionar con ellos sus trabajos, durante su viaje de regreso a España por Cartagena, donde debía entregarles sus colecciones para Madrid.

10. Acopiar quina y distribuirla por cuenta del gobierno en las provincias del Nuevo Reino ubicadas fuera del circuito comercial de la de Quito y Cuenca.

De la misión botánica asignada a López -puntos 1, 2, 6, 7, 8 y 9-, aprobada siempre por Gómez Ortega, el archivo de López que conserva la Biblioteca Nacional de Colombia (BNC) carece de información, excepto un oficio de Gálvez solicitando noticias de la Flora de Santafé y el envío de "simientes frescas de plantas útiles"46. El punto 9 no pudo realizarse

46 Oficio de Gálvez a López (Aranjuez, 6 de junio de 1781). Indiferente, 1554, f. 169v. AGI. 
porque la Rebelión de Túpac Amaru II (1780-1782) impidió a los botánicos del Perú emprender el viaje de regreso en la fecha prevista. Así, esta "misión botánica" se hallaba bajo la responsabilidad de un americano, aunque concebida y dirigida desde Madrid. No se han encontrado rastros de colecciones ni de correspondencia de López -si existieron- en el Jardín Botánico o en el Gabinete de Historia Natural de Madrid. Todo lo cual plantea interrogantes sobre el interés de España por los resultados de esta misión botánica en su colonia y el objetivo real del centralismo de la política científica de Gómez Ortega. También es legítimo preguntarse hasta dónde la Expedición al Perú y Chile es propiamente hablando, al menos en sus orígenes, producto de la política científica española.

Por lo relacionado con la quina - puntos 3, 4, 5 y 10- se observa que solo el 10 retuvo la atención de la Corona, convencida de que las validaciones de Madrid y París legitimaban automáticamente las quinas, dispensándola de cualquier intento por mejorar los saberes prácticos operantes en el terreno y a pesar del punto 5, más bien retórico. Tras obtener la validación del visitador para su "instrucción" sobre el conocimiento de los árboles de quina y "la elección de d[ic]hos vegetales, y sus diferencias; el modo de derribarlos, extraher, y beneficiar sus cortezas" ${ }^{47}$, López emprendió del 12 de diciembre de 1779 al 26 de febrero de $1780^{48}$ un viaje de reconocimiento de los lugares en que crecían estos árboles en las localidades de "Soacha, Bogotá, y Sipaquirá”. Entre el 2 de marzo y el 20 de abril de $1780^{49}$, realizó la primera compra por cuenta de la Real Hacienda, por valor de más de 2.000 pesos girados por las Cajas de Santafé ${ }^{50}$ el 11 de septiembre de 1779.

Nicolás Prieto Dávila, fiscal de la Audiencia de Santafé y miembro de una

47 Inspirándose sin duda en lo que se practicaba en Loja y en recomendaciones de Madrid. Sin embargo, en Susto, "El médico", 58, aparece que "ya en 1780 había escrito López su 'Memoria que podría servir de auxilio para el cultivo de los árboles de canela que nacen en las montañas calientes del Virreinato de Santa Fé de Bogotá" y en la nota (16): "Publicada en los Anales de Instrucción Pública de Bogotá, 1883, Tomo V, página 149”.

48 Expediente de López a Gálvez (Santafé, 31 de mayo de 1780). Indiferente, 1554, ff. 89-89v; 90-92v. AGI.

19849 Expediente de López a Gálvez (Santafé, 31 de mayo de 1780). Indiferente, 1554, f. 96. AGI.

50 Se ignora si esta cifra representa únicamente su salario. La Instrucción del 26 de noviembre de 1778 dispone que para 1779 López debe recibir aproximadamente 1.000 pesos de salario, porque se esperaba que desembarcara en Cartagena en junio. 
familia patricia, se rehusó a fenecer las cuentas alegando la no conformidad de los documentos allegados, falta de soportes para algunos gastos y excesiva cantidad de quina comprada en relación con el escaso consumo del reino. Tampoco aprobó la petición de 2.000 pesos adicionales para cosecheros y continuación del trabajo. Este argumento trasluce mala voluntad, pues las poblaciones a las que estaba destinada esta quina nunca habían consumido la lojana, ya que se trataba justamente de crear un nuevo mercado. Al negar esta partida, el fiscal desobedeció una orden del visitador $^{51}$, incluso tras haber recibido de manos de López el documento en que se indicaba no solo el nombre de los "sitios de donde se ha cortado [la quina], por lo que esta noticia puede conducir á los fines del establecimiento de este Ramo", sino también el de cada vendedor, su lugar de residencia y la cantidad aportada ${ }^{52}$. También se permitió instar a López a ocuparse de otros aspectos de su comisión - ¿la canela y la Flora de Santafe?-. El panameño entendía perfectamente "la repugnancia con que d[ic]ho Fiscal mira este negocio, por manejarlo yo"53. Gómez Ortega quizá comprendía mejor los obstáculos que enredaban a su protegido: "inútil y embarasosa prolixidad como me parece lo es la que exige el Fiscal de que en cada partida de Quina comprada se anote el terreno de donde se cogió, bastando a mi parecer que López forme para otros fines la Lista general de todos los territorios en que se descubran árboles de quina" ${ }^{\prime 54}$.

La gestión del fiscal desbordó el celo administrativo. Sus precauciones para evitar el despilfarro redujeron a la impotencia al visitador y al propio virrey. $\mathrm{Al}$ denunciar compras excesivas quería hacer creer que ignoraba estar destinada a la metrópoli. De este modo se reveló una gran limitación de la administración virreinal en sus altas instancias, y también la formidable capacidad de oposición de la élite criolla que detentaba una parte de la Junta General de Tribunales y el aparato ejecutivo de la administración donde operaban sus fichas. Conociendo la riqueza acumulada en la audiencia de Quito gracias a la quina, este sector se empeñó en socavar la gestión de

51 Gutiérrez de Piñeres a Prieto Dávila (Santafé, 11 de mayo de 1780) (copia). Indiferente, 1554 ff. 9292v. AGI.

52 Expediente de López a Gálvez (Santafé, 31 de mayo de 1780). Indiferente, 1554 ff. 93-98. AGI.

53 Expediente de López Ruiz a Gálvez (Santafé, 31 de mayo de 1780). Indiferente, 1554, f. 89. AGI.

54 Gómez Ortega a Gálvez (Madrid, 9 de mayo de 1779). Indiferente, 1557, ff. 165v. AGI. 
López, a quien por lo demás no era necesario anular de inmediato, pues se sabía que su comisión iba hasta 1781. Además, López estaba echando las bases de un probable y jugoso ramo de comercio, quedando el provecho de la información que recuperara, por iniciativa propia o gubernamental. Esta élite se oponía a un monopolio destinado a acaparar los derechos de explotación y comercio internacional de la quina santafereña, que crecía silvestre en tierras realengas (baldías) o en bosques privados, sustrayéndole de este modo una oportunidad de enriquecimiento. Llegado el momento se denunciaría ante la Corona la pobreza de los resultados alcanzados y se propondría un sucesor sensible a sus intereses. Para las reformas borbónicas, el hermetismo de las redes de influencia santafereñas hacia López era clave para asegurar la fidelidad del panameño con Madrid; en la realidad de la vida colonial es el escollo donde van a fracasar los proyectos que López encarna, aquello que pone en evidencia el precario realismo de la metrópoli con los contrapoderes locales.

López tuvo que conformarse en 1780 con su salario de 2.000 pesos. Impedido para continuar reconociendo otros bosques de quina, siguió administrando la que había adquirido y que permanecía almacenada en su residencia particular en Santafé ${ }^{55}$, con la esperanza de enviarla a Cádiz vía La Habana. Aseguraba a Gálvez que los cinco pesos pagados por arroba equivalían al precio corriente en Loja. Destacaba las ventajas de los montes santafereños sobre los del Perú, cuya quina era conducida a lomo de mula hasta Lima antes de alcanzar el puerto de Callao. Calculaba que los puertos de Honda, Cartagena y La Habana favorecían económicamente la exportación de la santafereña. Creó desde 1776 una red de corresponsales que le indicaron multitud de montes donde crecía, bien la quina, bien una canela silvestre diferente a la de Ceylán, montes que se proponía explorar. Su desempeño transcurría en medio de "persecuciones de mis émulos, que son muchos" 56 .

La investigación sobre la calidad de López avanzaba. El 28 de enero de

55 López a Gálvez, “Testimonio de las representaciones que ha hecho López” (Santafé, 31 de mayo de 1780). Indiferente, 1554, ff. 99-100. AGI.

56 López a Gálvez (Santafé, 15 de junio; 30 de junio, y 15 de julio de 1780) Indiferente, 1554, ff. 136139; 143-148; 149-149v. AGI. 
1780, Gálvez se dirigió a Gutiérrez de Piñeres: “[...] queriendo S[u]. M[ajestad]. saber con certeza la calidad y aptitud de D. Sebastián Josef López Ruiz, comisionado para el beneficio y descubrimiento de la quina, [...], informase reservadam[en]te lo q[u]e haya" ${ }^{27}$. Esta nueva orden fue expedida apenas un año después del nombramiento de López. ¿Acaso la sublevación indígena del Perú (1780-1782) obligó a la administración a prolongar la Expedición Ruiz y Pavón y, por ende, la comisión López? ¿Quería la administración continuar estableciendo el comercio de la quina santafereña, y remachar el acierto de Flórez y Gómez Ortega seleccionando a López? Sea como fuere, en junio de 1781 la comisión de López fue renovada, antes de que Gutiérrez de Piñeres cerrara el expediente remitido a Madrid el 31 de agosto de 1782. ¿Por qué se tomó cinco años el visitador para enviar su informe? ¿Acaso estimó por un tiempo que López era digno y capaz de desempeñarse? ¿Se sentía inhibido para adelantar sus pesquisas durante el mandato de Flórez, protector de López? ¿Carecía de una persona competente y disponible para confiarle las comisiones?

Madrid le renovó la comisión a López sine die para que continuara acopiando quina, o "a lo menos se conseguirá introducir el nuevo ramo de comercio [de la canela]" 58 . Suponía que el comisionado ya había comenzado la construcción de la estructura correspondiente, inspirándose en lo que había juzgado exitoso en Loja y aplicando las instrucciones de la metrópoli. También debían organizarse las existencias, almacenaje, envío y costos. Para ello la Corona le ordenó al visitador "protej[er] al botánico López y arregl[ar] los gastos y auxilios que regulase precisos". Le asignó "hasta dos mil p[eso]s para costear los gastos extraordinarios, cajones y cueros precisos para las remesas de Quina, Herbario, y demás q.[u] $]^{\mathrm{e}}$ ocurra" ${ }^{" 59 .}$ El rubro "Quinas" de las Cajas de Santafé desembolsó durante 1781 los 2.000 pesos del salario de López y los otros 2.000 prometidos por Gálvez y regis-

57 Citada en Gutiérrez de Piñeres a Gálvez, "Informe de López” (Santafé, 31 de julio de 1782). Santafé 661 , s. f. AGI.

58 Oficio de Gálvez a López (Aranjuez, 6 de junio de 1781). Indiferente, 1554, f. 170v. AGI.

59 Gálvez a Gutiérrez de Piñeres (Aranjuez, 6 de junio de 1781). Indiferente, 1557. f. 167. AGI. En carta de Cartagena (20 de diciembre de 1781), Gutiérrez de Piñeres acusa recibo a Gálvez de la Real Orden del 6 de junio de 1781. Indiferente, 1557, f. 171. AGI. 
trados "para compra de quina" a sus 40 años, el 6 de mayo de 1781 el comisionado contrajo matrimonio con María Begoña Aldana Silva, nacida en 1764 e hija de Pedro de Aldana Viscaya y Catalina de Silva y Herrera; Aldana había sido contador real y alguacil mayor de Antioquia hacia $1775^{61}$. La comisión de López operaba en medio de una coyuntura en que no habían sido sofocadas las sublevaciones en Perú ni en Nueva Granada y el panameño no podía "aguardar a la paz [con Inglaterra]", para "remitir muestras, aprovechándose de todos los correos que salgan de Cartagena en pliegos o paquetes de volumen moderado".

En 1782 los gastos volvieron a la normalidad de los 2.000 pesos de sueldo. En abril, López vio partir a Flórez, su protector en Nueva Granada. La muerte prematura del nuevo virrey Juan de Torrezar Díaz Pimienta, el 11 de junio de 1782, llevó a la cabeza del virreinato a Caballero y Góngora. Ya a "principios de 1782" este había logrado "sacar de [la mina de Nuestra Señora del Rosario en El Sapo] e inflamar de nuevo [a Mutis] para consumar la historia [natural] de este Reino [...], trayéndolo a esta ciudad y [a su] casa", el Palacio Arzobispal de Santafé6 ${ }^{62}$. El regreso de Mutis pudo incitar a López al trabajo. Desde hacía dos años y medio este último no se habría movido de la capital ni habría remitido quina a La Habana. Abandonó la ciudad el 22 de octubre, "para no malograr el verano que deb[e] aprovechar para [su] viaje a los Andaquies", en busca de canela, cuyo cultivo debía comenzar. Durante la peligrosa travesía, correspondió regularmente con Gálvez y Caballero y Góngora, aunque ocultándole a este último -y a Mutis- parte de sus observaciones ${ }^{63}$.

\section{LA CAÍdA DEL COMISIONADO}

Aunque la relación de viaje a los Andaquíes anunciaba descubrimientos y

60 Santafé 793 , s. f. AGI.

61 "Apellido Aldana en Colombia. Genealogías, historia, familias y descendientes del apellido Aldana", Genealogías de Colombia, s. f., Internet, 23 de agosto de 2013. <http://www.genealogiasdecolombia.co/apellidos/Aldana.aspx>

20262 Caballero y Góngora a Gálvez (Santafé, 31 de marzo de 1783), en Hernández de Alba, Archivo epistolar de Mutis, t. 1, passim, 117.

63 “Relación del viaje de Don Sebastián López Ruiz á la montaña de los Andaquíes en 1783”, La Revista Nueva 3.3 (1911): [217]-242; 220. 
envíos $^{64}$ a la metrópoli, los protectores de López en Madrid no lograron impedir su destitución, que se produjo el 29 de septiembre 1783. Acusado de "falso descubridor de la quina", en cierto modo se le expulsó del real servicio, perdió el honor y fue estigmatizado de por vida. Puesto bajo la autoridad de Mutis, ya director de la Expedición Botánica, toda su correspondencia destinada a la corte quedó formalmente sometida al criterio de este último ${ }^{65}$. Su obra pasada y venidera se convirtió en objeto de sospecha, que hoy perdura.

Aunque López nunca aceptó que Gálvez lo hubiese revocado, el ministro tenía la certeza de haber sido engañado y la convicción de que el descubridor era Mutis. Retractarse para Gálvez era más que reconocer públicamente un error de reclutamiento. Las reformas borbónicas de que era adalid habían desatado múltiples oposiciones. Una de ellas, la Revolución Comunera (1781), hubiera costado aún más a la Corona de no haber intervenido Caballero y Góngora, su pariente. Revocar a un protegido nombrado para reforzar una política de los poderes coloniales fue un acto de descentralización que implicó la transferencia de competencias en materia de finanzas, ciencia y comercio ${ }^{66}$. Este golpe suplementario infligido a la política colonial (tras la abolición de nuevos impuestos sobre el algodón, por ejemplo) fue celebrado por la élite criolla. En ella encontró Caballero y Góngora la oportunidad para restaurar la confianza entre los productores de la riqueza en el Nuevo Reino y su representación de la autoridad real.

La desgracia de López no fue rotunda. Destituido por la metrópoli, fue mantenido como comisionado por las autoridades virreinales que habían instigado su caída. Caballero y Góngora se hallaba "firmemente determinado a mantenerlo en su comisión, y representar por él a la Corte, significando al Rey que siempre convendrá conservarlo para el ramo de la quina y otros de que [la Expedición Botánica] no podrá jamás encargarse" ${ }^{\text {"7 }}$. Consecuente con ello y tras nombrarlo corresponsal del Real Jardín, si-

64 "Relación del viaje de S. J. L. R. a los Andaquies", La Revista Nueva.

65 Pérez y Fernández, Quinas, 19.

66 Amaya y Torres, "La Expedición”, 48-50.

67 Mutis a Eloy Valenzuela (1756-1834) (Santafé [poco después del $1^{\circ}$ de noviembre de 1783]), en Hernández de Alba, Archivo Epistolar de Mutis, t. 1, 145. 
multáneamente con Mutis ${ }^{68}$, el 19 de agosto de 1784 Gálvez expidió una nueva orden disponiendo emplear a López, en vista de la necesidad del Nuevo Reino de hombres con "algún conocimiento en los Reynos vegetal, animal y mineral" ". Desde el 20 de mayo de 1784, interesado en limpiar su honor, López había remitido a Caballero y Góngora una Cronología del descubrimiento de la quina de Santafé. El intento falló y su situación se complicó en 1785 cuando se le prohibió ir a la corte a defenderse. No obstante, varias misiones le fueron confiadas, aunque su desempeño no satisfizo a Caballero y Góngora:

"[s]u ningún tino en medir, combinar y reglar las noticias, su poco sigilo y mucho amor a representar entre las gentes su extraordinaria ligereza y precipitación en todos los viajes que hasta ahora le he obligado a hacer con miras de averiguar su carácter y finalmente los muchos gastos que acostumbra tener en sus excursiones me obligan a no pensar en él para ningún asunto"70.

La Caja Matriz de Santafé no conserva prueba de pagos a López entre 1783 y 1785, aunque el interesado aseguró haber recibido sus 2.000 pesos anuales durante aquel trienio. El 18 de mayo de 1785, el Tribunal Mayor de Cuentas de Santafé ordenó reembolsarle 204 pesos, 4 reales y 25 maravedíes por gastos impendidos en sus viajes como comisionado para el

68 Mutis a Valenzuela (Santafé, 31 de diciembre de 1783), en Hernández de Alba, Archivo epistolar de Mutis, t. 1, 150.

69 Gálvez a Caballero y Góngora, “Orden” (19 de agosto de 1784). Fondo Pineda, IV, 3 (80). BNC.

70 Caballero y Góngora a Mutis (Turbaco, 26 de septiembre de 1786), en Hernández de Alba, Archivo epistolar de J. C. Mutis, t. 1, 59. Este testimonio no concuerda ciertamente con la declaración de Francisco Bianchi, contador del comisionado López, legalizada en Santafé el 14 de septiembre de 1784: "hallándome con deliberación de ausentarme de [Santafé], para los efectos que haya lugar y en derecho correspondan a don Sebastián López Ruiz, declaro con toda pureza y verdad que desde el año pasado de 1780 hasta el presente he manejado y han estado a mi cargo las cuentas de los gastos impendidos en la administración de los acopios de quina, llevando con la formalidad que se requiere y que en todas ellas ha procurado el mencionado don Sebastián, la mayor economía, pureza e integridad a favor de los reales intereses que ha manifestado; que por mi mano se han pagado todas las cantidades de costos y gastos que en dichos asuntos se han impendido arreglando las cuentas en toda fidelidad que el prenotado don Sebastián ha presentado en estas reales cajas para el desempeño de las reales comisiones". Notaría Segunda, Santafé, Tomo 166, Año 1784, ff. 264-264v. AGN. Hay que guardarse de pensar Bianchi tenía competencia para juzgar lo excesivo o no de los gastos de López, particularmente en viajes, como el que emprendió a los Andaquíes a finales de 1782 o principios de 1783. 
acopio de la quina y otros ramos, que se elevaron a 904 pesos, 4 reales y 25 maravedíes, de los cuales había recibido 700 pesos en Cartagena. Tales viajes lo habían conducido a "las Montañas de Ocaña, Simití y Guamocó, de la Provincia de Cartagena y Santa Marta" ${ }^{\text {" }}$. El $1^{\circ}$ de septiembre de 1804, López confirmaba al virrey Antonio Amar y Borbón (1742-1826) que "[...] despues de mi buelta á este Reyno remití á la Corte, una sola vez. los diez y ocho cajones y dos churlas del propio específico, q[u]e resultó ser idéntico en su especie y efectos á la quina selecta de la provincia de Quito, según lo expresa la R[ea]l Or[de]n de 2 de marzo de $1785^{\text {"72 }}$. Además, las cartas cuentas de 1786 y de 1787 prueban que López percibió su pensión de 1.000 pesos anuales, conforme a la decisión de Caballero y Góngora $^{73}$, sin que se sepa si durante estos años la administración le asignó alguna función, lo que a priori parece inverosímil porque desde el 19 de septiembre de 1783 Caballero y Góngora le había transferido al fraile franciscano Diego García las funciones de López ${ }^{74}$.

López no figura entre los pensionados reales en las cartas cuentas de la Caja de Santafé de 1788 a 1802. La contabilidad gubernamental de 1803 señala de nuevo y por última vez un pago de 1.000 pesos que no corresponde a su pensión, ya que por Decreto del 3 de agosto de 1803 del virrey Pedro Mendinueta (1736-1825), López recuperó el puesto de comisionado para la quina, en reemplazo de Louis de Rieux (¿1755?-¿1840?). Mendinueta sostenía que como López disfrutaba "sin destino el sueldo de mil pesos anuales", "no se le abonará otro sueldo que el que ha disfrutado hasta ahora, del que se tomará razón en el Tribunal de Cuentas, caxas Reales de esta Capital y de Honda"75. Contrario a lo que López siempre sostuvo, el

71 "Certificación del Tribunal Mayor y Real Audiencia de Cuentas de Santafé sobre el balance de gastos presentado por Sebastián José López Ruiz de sus viajes como comisionado para el acopio de la quina y otros ramos". Fondo Pineda, IV, 5 (82-84). BNC.

72 López al virrey Antonio Amar y Borbón, “Representación” (copia). Fondo Pineda, V, 6 (169-171). BNC.

73 "Al respecto de 1.000 pesos anuales, concedidos por Real Cédula de 24 de noviembre de 1778, esto es, que aunque se le asignó mayor sueldo últimamente por Orden del Excelentísimo Virrey [Caballero y Góngora] se le restringió al de los 1.000 pesos". Santafé 795, s. f. AGI.

74 Luis Carlos Mantilla y Santiago Díaz-Piedrahita, Fray Diego García, su vida y su obra científica en la Expedición Botánica (Santafé de Bogotá: Academia Colombiana de Ciencias Exactas, Físicas y Naturales, 1992), 20.

75 "Decreto del virrey Mendinueta nombrando a López comisionado para el reconocimiento, recolección y envío de quina a España" Fondo Pineda, V, 2 (161-163). BNC. 
decreto de Mendinueta sugiere que disfrutó de una pensión de 1000 pesos de 1786 a 1802. Puede imaginarse la decepción de López quien al poco tiempo solicitó el cargo de Contador General de Tributos de Quito, con una dotación de 1800 pesos anuales, que obtuvo el 5 de agosto de $1803^{76}$. Hay que notar que con apoyo en un documento del AGI (117_2_20), el historiador J. A. Susto sostiene que: "El 19 de Septiembre de 1804 se le nombró [a López] para el cargo de Contador de Tributos de Quito"77. Sin embargo, para la historiadora Pilar Gardeta, "los asuntos que [López] mantenía pendientes en la capital neogranadina hicieron que retrasara su traslado hasta mediados de 1804"78. Varios documentos conservados en la BNC indican que López se desempeñó como comisionado para el acopio de quina al menos hasta el 24 de octubre de $1804^{79}$. Al respecto, las Cajas Reales de Santafé tampoco parecen conservar ningún soporte de sueldo pagado a López en 1804; se ignora si las Cajas de Quito desembolsaron algún pago al panameño durante este año.

\section{LAS CIFRAS}

La consolidación de datos de las comisiones de López resultó de una búsqueda en el Archivo de la Caja Matriz de Santafé, un archivo acumulado de 40 tomos de unos mil folios cada uno, que conserva la Sección del Archivo Anexo I (SAAI) del AGN. La consulta del AGI complementó esta información, toda vez que Colombia no conserva la colección completa de los citados libros manuales. La Tabla 2 presenta información recuperada de las citadas cartas cuentas santafereñas (en negrita), junto con información indirecta (en gris). Esta última sugiere un acercamiento más completo al conjunto de erogaciones gubernamentales a favor de López.

Los datos enseñan que para los más de 20 años en que el Real Erario

76 Gardeta, S. J. López Ruiz, 41: "vería [López] cumplidas una parte de sus aspiraciones, por las que tanto había luchado durante toda su vida. El 5 de agosto [de 1803] obtuvo del rey el nombramiento como Contador General de Tributos de Quito, empleo que tenía una asignación de 1.800 pesos anuales" y nota 119, Quito, Leg. 227, AGI. Para la fecha del 7 de febrero de 1804: Real Orden comunicada por el Amar a López. Fondo Pineda, XI, 4 (573). BNC.

77 Susto, "El médico", 61 y nota 29.

78 Gardeta, López, 42.

79 Amar a López, Santafé, 24 de octubre de 1804, Fondo Pineda, V, 9 (174). BNC. 
desembolsó recursos para las comisiones pueden identificarse tres fases: 1776-1782, 1783-1797 y 1801-1803, que coinciden grosso modo con los periodos en que López y Mutis detentaron el cargo de "comisionado". Los periodos también se diferencian por la magnitud y volatilidad de los flujos de caja. Durante la primera fase dirigida por el panameño, las comisiones recibieron en Santafé 10.410 pesos para compra de quina y sueldo de López. Estos dineros se gastaron de manera casi uniforme a lo largo de los años, con muy poca volatilidad. Durante la etapa dirigida por el gaditano, el mismo concepto presentó un salto cuantitativo al recibir la suma de 163.392 pesos con cambios bruscos de año a año. En 1788, cuando los gastos alcanzaron su punto máximo, el de compra de quinas llegó a representar el $16 \%$ del gasto efectivo de la Caja Matriz, superando al enorme desembolso eclesiástico y representando casi el $80 \%$ de los situados enviados a la Costa ${ }^{80}$. Cuando López retomó efímeramente la comisión, los gastos volvieron a sus modestos niveles iniciales. Las quinas santafereñas no contaron con la demanda efectiva que esperaban López y Mutis del mercado internacional. Habría que esperar diez años más para efectivar su promoción y venta en Europa, lo que obligó al virrey Francisco Gil de Taboada Lemus (1739-1809) a paralizar las comisiones. Aún en 1798 se seguían pagando deudas atrasadas a los cosecheros vinculados entre 1787 y 1790 .

\section{Tabla 2.}

Viajes, comisión y pensión de Sebastián José López Ruiz asumidos por las Reales Cajas de Santafé, Honda y Cartagena

\begin{tabular}{|l|c|c|}
\hline \multicolumn{1}{|c|}{ Concepto } & Año & Pesos plata \\
\hline Sueldo de escribano de la Secretaría & $\begin{array}{c}\text { Desde su nombramiento } \\
\text { en 1776 }\end{array}$ & - \\
\hline Costos de dos viajes a Tena & Agosto de 1776 & 401 \\
\hline Sueldo de escribano de la Secretaría & 1777 & - \\
\hline Ídem & 1778 & - \\
\hline Primer viaje a Madrid & $1778-1779$ & - \\
\hline Sueldo de comisionado & 1779 & 2000 \\
\hline Ídem & 1780 & 2000 \\
\hline Ídem & 1781 & 2000 \\
\hline
\end{tabular}

80 José Joaquín Pinto Bernal, “Entre Colonia y República. Fiscalidad en Ecuador, Colombia y Venezuela 1780-1845”, (tesis doctoral, Universidad Nacional de Colombia sede Bogotá, 2015, Anexo 1). 


\begin{tabular}{|c|c|c|}
\hline Concepto & Año & Pesos plata \\
\hline "Para compra de quina" & 1781 & 2000 \\
\hline Sueldo de comisionado & 1782 & 2000 \\
\hline Costos del viaje a los Andaquíes & $1782-1783$ & - \\
\hline Sueldo de comisionado & 1783 & 2000 \\
\hline Ídem & 1784 & 2000 \\
\hline Ídem & 1785 & 2000 \\
\hline Viaje a Cartagena y Santa Marta & 1785 & 700 \\
\hline $\begin{array}{l}\text { Comisionado para el acopio de quina e introducir el ramo de } \\
\text { la canela }\end{array}$ & 1785 & 204 \\
\hline Pensión & 1786 & 1000 \\
\hline Ídem & 1787 & 1000 \\
\hline Ídem & 1788 & 1000 \\
\hline Ídem & 1789 & 1000 \\
\hline Ídem & 1790 & 1000 \\
\hline Ídem & 1791 & 1000 \\
\hline Ídem & 1792 & 1000 \\
\hline Ídem & 1793 & 1000 \\
\hline Ídem & 1794 & 1000 \\
\hline Ídem & 1795 & 1000 \\
\hline Ídem & 1796 & 1000 \\
\hline Ídem & 1797 & 1000 \\
\hline Ídem & 1798 & 1000 \\
\hline Ídem & 1799 & 1000 \\
\hline Ídem & 1800 & 1000 \\
\hline Ídem & 1801 & 1000 \\
\hline Ídem & 1802 & 1000 \\
\hline Pensión/sueldo de comisionado & 1803 & 1000 \\
\hline
\end{tabular}

Fuente: Elaboración propia con base en información recuperada en: Archivo General de la Nación (Bogotá) (AGN), Sección Archivo Anexo I (SAA I), Real Hacienda, t. 8-16; Archivo General de Indias (Sevilla, España) (AGI), Santafé, tomos 791-802; BNC, Fondo Pineda IV, 5 (82-84), V, 2 (161-163)

¿Qué balance puede sacarse de este movimiento financiero? Para la Real Hacienda y desde un punto de vista de estricto flujo de caja, el resultado no pudo ser más negativo. López y Mutis solo pudieron vender 253 pesos contra los 172.983 pesos que costó el proyecto. Caballero y Góngora ha- 
bía prometido una "utilidad líquida" de 600.000 pesos para 1790; además, propuso reemplazar los estancos de pólvora y rapé por el de quina ${ }^{81}$.

Para Mutis como para López la experiencia con la quina se tradujo en dos vías distintas. Empeñado en realizar sus proyectos con apoyo de la Real Hacienda, el segundo logró ser reintegrado en 1803 en el cargo durante un año. A corto plazo, para Mutis significó una contrariedad la magnitud de los dineros invertidos por el rey; a largo plazo, las comisiones le brindaron un aprendizaje científico del uso de la quina y la posibilidad de poner a punto métodos de corte, embalaje y, sobre todo, percibir el estado del mercado. Esta experiencia servirá a los mercaderes cuando luego de 1799 inicien la exportación masiva del producto usando el método de Mutis, quien se implicó en el negocio al regreso de España de su sobrino Sinforoso Mutis Consuegra (1773-1822).

\section{Conclusiones}

Por primera vez e independientemente del testimonio de López, la historiografía logra hacerle un seguimiento a sus comisiones. Debía descubrir, investigar e iniciar la explotación de las quinas de Santafé, y formar un herbario asociado con una "Flora de Santafé", concebida para ser editada en el Real Jardín. Tal seguimiento permite comprender cómo, desde antes de su creación, esta "expedición", apéndice de la del Perú y Chile, fue percibida de manera diferente de un lado y otro del Atlántico. Para España, el reto era suplir la creciente escasez de quina de Loja. En el Nuevo Reino, el honor derivado de servir al rey persuadió al médico panameño a convertirse en explorado guiado por la descripción de Charles-Marie de La Condamine (1701-1774). Construyó saberes y tecnologías para explotar y exportar quinas, considerados científicos por ser pioneros. La metrópoli dejó al comisionado en libertad para trabajar fuera de cualquier control, según su estilo personal, frente a una élite santafereña ilustrada afecta a Mutis, que entorpeció su acción y capitalizó sus éxitos en cada ocasión.

81 "Relación que presenta el Obispo de Córdoba", en Relaciones e informes de los gobernantes de la Nueva Granada, t. 3, compilador Germán Colmenares (Bogotá: Banco Popular, 1989), 482. 
Estos intereses discordantes evidencian que Madrid ignoraba o quería ignorar la realidad de los contrapoderes neogranadinos. Tras la Revolución de los Comuneros y el cambio de virrey, las protecciones se desplazaron. Madrid reconoció haberse dejado engañar por López y sus protectores sobre la primacía del descubrimiento de bosques de quina en Santafé. Este "error" del Ministerio de Indias comprometió buena parte de las reformas borbónicas, provocando una descentralización política que implicó más transferencia de competencias en materia de finanzas, ciencia y comercio a las autoridades neogranadinas. La destitución de López no se oficializó inmediatamente; en un primer momento, se le mantuvo en funciones, bajo la autoridad de Mutis; tres años más tarde fue pensionado.

Pese a lo anterior, los planes con la quina no fueron abandonados. Aquí hemos mostrado que el correspondiente presupuesto creció de manera abrumadora: se trataba de crear el estanco de la quina. Este proyecto pudo ser porque las muestras proporcionadas por López a Flórez habían sido validadas por Madrid y París como de quina legítima y terapéutica. Queda por establecer cuáles fueron los saberes prácticos que López implementó; más generalmente, qué información por él recuperada se movilizó a la hora de proyectar y poner en funcionamiento la empresa estatal de quinas (1787-1790). Es improbable que Mutis y sus aliados hayan dejado pistas de su deuda con el médico panameño; a pesar de las críticas, López encarnaba lo mejor que podía producir la universidad americana. Los ataques sobre su origen, el descrédito de su persona, las trabas a sus actividades y la sombra que se proyectó sobre sus comisiones dan cuenta del carácter segregacionista que conoció el inicio de la ciencia en Nueva Granada. La relación entre raza y ciencia en Colombia queda aquí sugerida. Este atributo de la ciencia neogranadina explica que solo en fecha reciente se haya descubierto a López, Botánico del Rey. Tal resurgimiento no ha estado acompañado de un trabajo de arqueología: los investigadores continúan prisioneros de los discursos dictados por las pasiones de la época, cuando no sometidos a sentimientos nacionalistas.

Aquí la producción de saberes es indisociable del funcionamiento de la administración pública; no solo de la administración económica, sino sobre todo de la alta administración política. Nuestros centros científicos, dependientes de la administración, establecieron relaciones muy precisas con 
la sociedad -comerciantes, hacendados, cosecheros, pintores-. Se impone tener claro que el científico es además un administrador de dinero y de productos al servicio del Estado, y que puede llegar a explotar a su favor una posición de que ha gozado al servicio de ese mismo Estado. Los resultados de este trabajo invitan a ampliar la investigación en direcciones diferentes a las anunciadas en la introducción. Se requiere una comprensión de la dinámica de los poderes y contrapoderes. La resultante se revelará como la capacidad de acción de la administración colonial. En este marco, si alguna de estas fuerzas trataba de exagerar su juego la acción se tornaba peligrosa cuando no caótica. La invitación a asociar la historia de las ciencias con la de la administración pública sigue a la orden del día.

\section{Bibliografía}

\section{Fuentes Primarias}

\section{Archivo}

Archivo General de Indias, Sevilla, España (AGI).

Archivo Nacional del Ecuador, Quito, Ecuador (ANE).

Archivo General de la Nación, Bogotá, Colombia (AGN).

Biblioteca Nacional de Colombia, Bogotá, Colombia (BNC).

Biblioteca de Palacio, Madrid, España.

Fondo Pineda, t. 196.

Indiferente, 1554, 1557.

Notaría Segunda, Santafé, t. 166.

Protocolos, Notaría Tercera, t. 78.

Santafé, 558, 661, 791-802.

Sección Anexo I (SAAI), Real Hacienda, t. 1-40.

\section{Documentación primaria impresa}

"Relación del viaje de Don Sebastián López Ruiz, Panameño, á la montaña de los Andaquíes (Territorio del Caquetá hoy) en 1783, por comisión real". La Revista Nueva 3.3 (1911): [217]-242. Impreso.

"Relación que presenta el Obispo de Córdoba". En Relaciones e informes de los gobernantes de la Nueva Granada, t. 3, compilador Germán Colmenares. Bogotá: Banco Popular, 1989. Impreso. 


\section{Fuentes Secundarias}

Amaya, José Antonio. Mutis, apóstol de Linneo: Historia de la botánica en el Virreinato de la Nueva Granada (1760-1783), 2 tomos. Trad. José Antonio Amaya, con apoyo en una versión preliminar de $\mathrm{M}^{\mathrm{a}}$ Yolanda Medina. Bogotá: ICANH, 2006. Impreso.

Amaya, José Antonio, y James Vladimir Torres Moreno. “La Expedición Botánica a la luz de las cifras 1783-1816”. Ensamblando Estados, editado por Olga Restrepo Forero. Bogotá: Universidad Nacional de Colombia, Facultad de Ciencias Humanas, Centro de Estudios Sociales (CES), 2013, 41-75. Impreso.

Barbier, Jacques A., y Herbert S. Klein. "Las prioridades de un monarca ilustrado: El gasto público bajo el reinado de Carlos III". Revista de Historia Económica 3.3 (1985): 473-495. Internet. 15 de agosto de 2014 <http://orff.uc3m.es/bitstream/handle/10016/1638/RHE1985-III-1-Barbier.Herbert.Klein.pdf?sequence=1>

Barras de Aragón, Francisco de las. "Mutis en el Archivo de Indias". Mss cit. Quinas de la Real Expedición Botánica del Nuevo Reino de Granada. Flora de la Real Expedición Botánica del Nuevo Reino de Granada, Vol. 44. Reds. Enrique Pérez Arbeláez y Francisco Fernández de Soto Morales. Madrid: Instituto de Cultura Hispánica, 1957. Impreso.

Durán Díaz, Joaquín. Estado general del Virreinato de Santafé de Bogotá en el año de 1794. Bogotá: Banco de la República, 2012. Impreso.

Fernández Pérez, Joaquín, Cristina Jiménez Artacho y José Fonfría Díaz. "Las quinas de Caldas". Actas VIII Congreso de la Sociedad Española de Historia de las Ciencias y de las Técnicas, coordinadores José Javier Escribano Benito, Luis Español González y Mán Ángeles Martínez García. Logroño: Universidad de la Rioja, 2004, [559]-583. Internet. 15 de mayo 2014. <http:/ / dialnet.unirioja.es/descarga/articulo/1091020.pdf>

Gardeta Sabater, Pilar. Sebastián José López Ruiz (1741-1832). Sus escritos médicos y el ejercicio de la medicina en el Virreinato de Nueva Granada durante la segunda mitad del siglo XVIII. Málaga: Universidad de Málaga, 1996. Impreso.

Hernández de Alba, Guillermo. Archivo epistolar del sabio naturalista don José Celestino Mutis, t. 2. Bogotá: Kelly, 1968. Impreso. 
Mantilla, Luis Carlos, y Santiago Díaz-Piedrahita. Fray Diego García, su vida y su obra científica en la Expedición Botánica. Bogotá: Academia Colombiana de Ciencias Exactas, Físicas y Naturales, 1992. Impreso.

Meisel, Adolfo. Crecimiento, mestizaje y presión fiscal en el Virreinato de la Nueva Granada, 1761-1800. Cartagena: Centro de Estudios Económicos Regionales (CEER), 2011. Internet. 15 de mayo de 2014. <http://www.banrep.gov.co/sites/default/files/publicaciones/archivos/chee_28.pdf>

Pinto Bernal, José Joaquín. "Entre Colonia y República. Fiscalidad en Ecuador, Colombia y Venezuela 1780-1845". (Tesis doctoral. Universidad Nacional de Colombia, sede Bogotá, 2015). Impreso.

Silva, Renán. Los ilustrados de Nueva Granada, 1760-1808. Medellín: Banco de la República, EAFIT, 2002. Impreso.

Susto, Juan Antonio. "El médico y naturalista panameño Dr. Sebastián José López Ruiz (1741-1832)”. Lotería 6.67 (1961): 54-69. Internet. 15 de mayo de 2014. <http://bdigital.binal.ac.pa/loteria/descarga. php?f=1961_LNB/1961_067_LNB.pdf >

Thuillier, Guy. Pour un histoire de la bureaucratie en France. 2 tomos. París: Comité pour l'histoire économique et financière de la France (CHEFF), IGPDE, 1999. Impreso.

Torres, James. Minería y moneda en el Nuevo Reino de Granada. El desempeño económico en la segunda mitad del siglo XVIII. Bogotá: ICANH, 2013. Impreso.

\section{Consultado en la red}

"Apellido Aldana en Colombia. Genealogías, historia, familias y descendientes del apellido Aldana". Genealogías de Colombia, s. f., Internet, 23 de agosto de 2013. <http://www.genealogiasdecolombia. co/apellidos/Aldana.aspx>

Para citar este artículo: Amaya, José Antonio y Torres Moreno, James Vladimir. "Ciencia y economía en el Nuevo Reino de Granada. Las comisiones de Sebastián José López Ruiz, 1778-1803”, Historia Caribe Vol. XI No. 29 (Julio-Diciembre 2016): 183-213. DOI: http://dx.doi. org/10.15648/hc.29.2016.8 